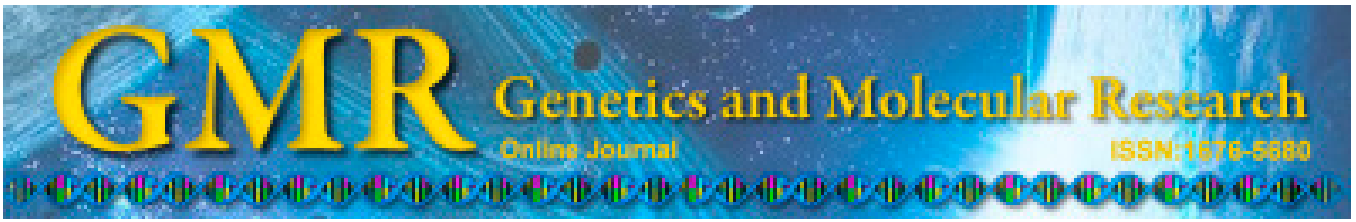

\title{
Cluster analysis of Pinus taiwanensis for its ex situ conservation in China
}

\author{
X. Gao ${ }^{1}$, L. Shi ${ }^{2}$ and $\mathrm{Z}$. Wu ${ }^{3}$ \\ ${ }^{1}$ College of Life Science, Anhui Normal University, Wuhu, China \\ ${ }^{2}$ International Center for Bamboo and Rattan, Beijing, China \\ ${ }^{3}$ School of Forestry and Landscape Architecture, \\ Anhui Agricultural University, Hefei, China \\ Corresponding author: L. Shi \\ E-mail: leishi@icbr.ac.cn
}

Genet. Mol. Res. 14 (2): 5845-5855 (2015)

Received October 30, 2014

Accepted January 19, 2015

Published June 1, 2015

DOI http://dx.doi.org/10.4238/2015.June.1.1

\begin{abstract}
Pinus taiwanensis Hayata is one of the most famous sights in the Huangshan Scenic Resort, China, because of its strong adaptability and ability to survive; however, this endemic species is currently under threat in China. Relationships between different $P$. taiwanensis populations have been well-documented; however, few studies have been conducted on how to protect this rare pine. In the present study, we propose the ex situ conservation of this species using geographical information system (GIS) cluster and genetic diversity analyses. The GIS cluster method was conducted as a preliminary analysis for establishing a sampling site category based on climatic factors. Genetic diversity was analyzed using morphological and genetic traits. By combining geographical information with genetic data, we demonstrate that growing conditions, morphological traits, and the genetic make-up of the population in the Huangshan Scenic Resort were most similar to conditions on Tianmu Mountain. Therefore, we suggest that Tianmu Mountain is the best choice for the ex situ conservation of $P$. taiwanensis. Our results provide
\end{abstract}


a molecular basis for the sustainable management, utilization, and conservation of this species in Huangshan Scenic Resort.

Key words: Climatic factor; Custer analysis; Genetic marker; Morphological trait; Pinus taiwanensis

\section{INTRODUCTION}

Pinus taiwanensis Hayata (also known as Pinus hwangshanensis) is mainly found in the mountains of the southeastern provinces of China, including Anhui, Fujian, Hunan, Jiangxi, Zhejiang, and Taiwan, at altitudes ranging from 750 to $2800 \mathrm{~m}$ (Figure 1) (Zhang, 1990). This endemic species is an important component of the Chinese natural landscape, and attracts tourists to the Huangshan Scenic Resort in Anhui Province, China. Because of the high degree of flexibility (plasticity) of its crown, P. taiwanensis often takes on various distinctive shapes under strong wind conditions. In addition, this species can survive on cliffs under harsh conditions (e.g., barren soils and low temperatures), and exhibits an extraordinary adaptability and capacity for survival. As a result, $P$. taiwanensis is a crucial component of the famous scenery of the Huangshan Scenic Resort, which has been a world-class geopark and a natural and cultural heritage site since 1990 .

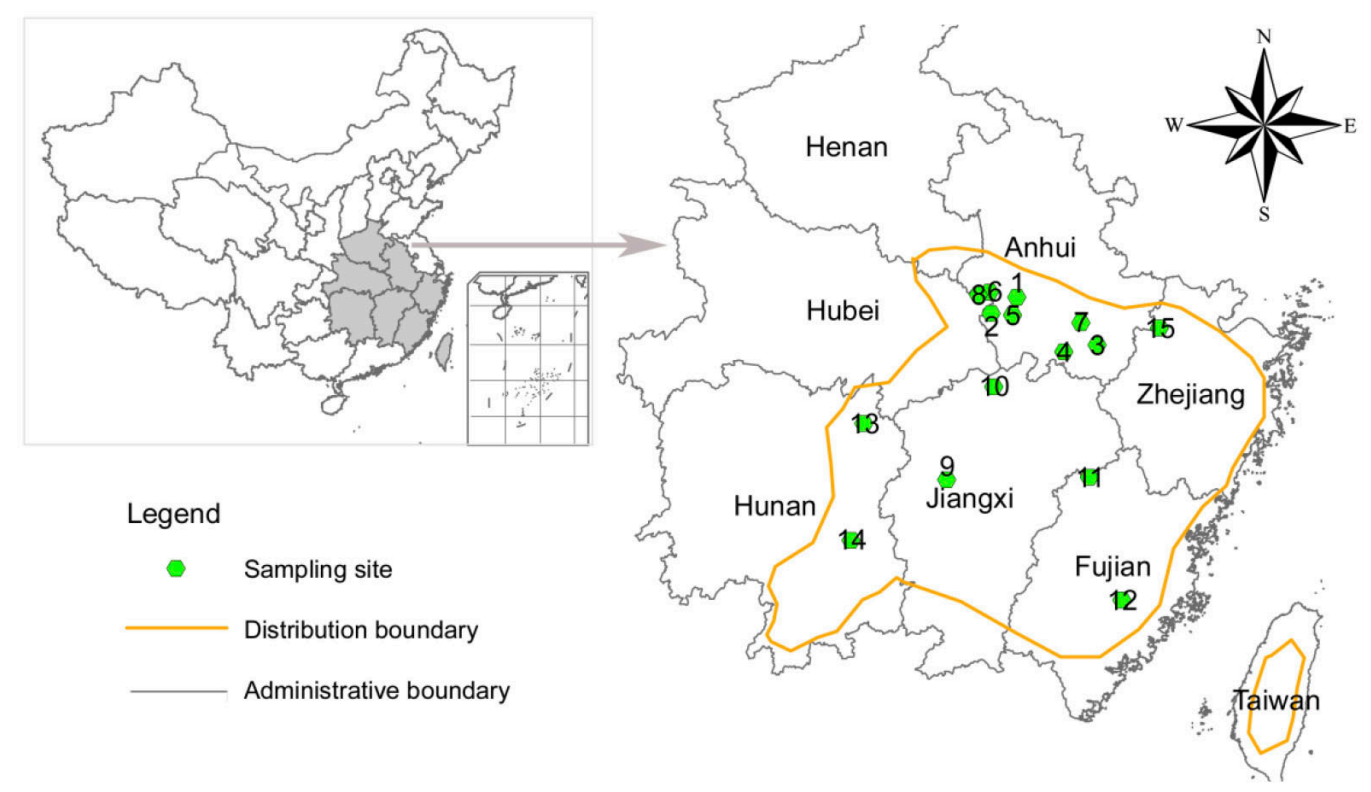

Figure 1. Distribution of 15 Pinus taiwanensis sampling sites. The sampling sites are listed in Table 1.

However, the species is threatened in the Huangshan Scenic Resort. The threat stems, in part, from Bursaphelenchus xylophilus, which is a nematode pest of pines (Yang et al., 2004). This species was introduced into China in 1982, and has recently appeared in many provinces, including Anhui Province (Robinet et al., 2009). Consequently, P. taiwanensis is 
under threat of infestation by this species in the Huangshan Scenic Resort. In addition, the flourishing tourism industry in the resort is another reason for the decreased species diversity of $P$. taiwanensis communities (Wu et al., 2006). Therefore, it is crucial to protect $P$. taiwanensis, particularly in Huangshan.

In general, rare species are usually protected by in situ and/or ex situ approaches (Barrett et al., 1991; Nevo, 1998; Clement et al., 2009). In situ conservation practices preserve both genetic and ecological information, and may confer distinct benefits (Brush, 1995). A possible approach would be to set up nature reserves in the Huangshan Scenic Resort for the in situ conservation of the pine, but such an approach may not be viable, as it is difficult to transform a scenic resort into a nature reserve. Therefore, ex situ conservation may be the most suitable choice. A better understanding of the genetic variation and distinctiveness of $P$. taiwanensis populations is needed before the ex situ conservation of this species can be successful (McGregor et al., 2002).

Previous studies on the genetic diversity and divergence of $P$. taiwanensis have mainly focused on morphological traits subjected to environmental influences (Sheue et al., 2003). But the linking between ecological attributes/traits and enviromental factors was not fully explored. Combining ecological data with geographical information system (GIS) data makes an in-depth analysis of dominant traits possible (Grubesic and Murray, 2001; Tang et al., 2011). The importance of using statistical techniques that incorporate spatial information at different levels when studying species distribution has been demonstrated previously (e.g., Higgins et al., 1999; Jetz and Rahbek, 2002). Additionally, polymerase chain reaction (PCR)based techniques, such as amplified fragment length polymorphism (Tyrka, 2004), simple sequence repeats (Martin et al., 2011), inter simple sequence repeats (Nayak et al., 2013), and random amplified polymorphic DNA (RAPD) (Dursun et al., 2010) are widely employed, which enable the discrimination of closely related genotypes (Singh et al., 2013). Therefore, the combined use of morphological and molecular markers facilitates a comparative analysis of phenotypes from field experiments, and genotypes from laboratory studies (Nazar and Mahmood, 2011).

The objective of the present study was to determine the genetic variability and relationships between 15 P. taiwanensis specimens from different regions of China, based on morphological and RAPD markers, and to find a suitable location where the features of the $P$. taiwanensis population (i.e., living environment and genetic origin) are similar to those of the Huangshan Scenic Resort. Put simply, our aim was to find the most suitable location for the $e x$ situ conservation of $P$. taiwanensis.

\section{MATERIAL AND METHODS}

\section{Plant materials}

Fifteen sampling sites in mainland China were established in the natural range of $P$. taiwanensis, based on the graticule method and mountain range characteristics (Figure 1). At these sites, needles and cones from healthy and mature parent trees were randomly selected and mixed. Fresh leaves were collected and stored at $-20^{\circ} \mathrm{C}$ for future DNA extraction.

Climatic data, including the frost-free period, annual precipitation (AP), annual mean temperature (AMT), mean temperature in January and July, sunshine duration, relative humid- 
ity (RH), and accumulated temperatures higher than $10^{\circ} \mathrm{C}$ were also collected. The geographical location of each sampling site was measured (see Table 1 for more details) with a Garmin GPS- $90^{\mathrm{TM}}$.

Table 1. Pinus taiwanensis sampling sites and their climatic conditions.

\begin{tabular}{|c|c|c|c|c|c|c|c|c|c|c|c|c|}
\hline No. & $\begin{array}{l}\text { Geographical } \\
\text { origin }\end{array}$ & $\begin{array}{l}\text { Long. } \\
\left({ }^{\circ}\right)\end{array}$ & $\begin{array}{l}\text { Lat. } \\
\left({ }^{\circ}\right)\end{array}$ & $\begin{array}{l}\text { Alt. } \\
(\mathrm{km})\end{array}$ & $\begin{array}{l}\text { FFP } \\
\text { (days) }\end{array}$ & $\begin{array}{c}\mathrm{AP} \\
(\mathrm{mm})\end{array}$ & $\begin{array}{l}\text { AMT } \\
\left({ }^{\circ} \mathrm{C}\right)\end{array}$ & $\begin{array}{c}\mathrm{MT} \mathrm{Ja} \\
\left({ }^{\circ} \mathrm{C}\right)\end{array}$ & $\begin{array}{c}\mathrm{MT} \mathrm{Ju} \\
\left({ }^{\circ} \overline{\mathrm{C}}\right)\end{array}$ & $\begin{array}{l}\text { SD } \\
\text { (h) }\end{array}$ & $\begin{array}{l}\mathrm{RH} \\
(\%)\end{array}$ & $\begin{array}{l}\mathrm{CT} \\
\left({ }^{\circ} \mathrm{C}\right)\end{array}$ \\
\hline 1 & Wanfo Mt. & 116.55 & 31.05 & 1.07 & 220 & 1574 & 13.6 & -0.4 & 22 & 1700 & 85 & 4700 \\
\hline 2 & Miaodao Mt. & 116.10 & 30.80 & 1.15 & 210 & 1450 & 11.70 & -0.2 & 23 & 1730 & 78.5 & 3900 \\
\hline 3 & Huangshan Mt. & 118.13 & 30.12 & 1.50 & 225 & 1982 & 7.90 & -0.4 & 18 & 1703.6 & 80 & 4000 \\
\hline 4 & Guniujiang Mt. & 117.45 & 30.05 & 1.00 & 246 & 1650 & 15.60 & 0.1 & 21 & 1720 & 80 & 5000 \\
\hline 5 & Tianzhu Mt. & 116.45 & 30.73 & 1.30 & 235 & 1900 & 20.00 & 0.1 & 20 & 1800 & 78 & 4210 \\
\hline 6 & Majiahe & 116.10 & 31.12 & 1.10 & 225 & 1915 & 15.90 & 0.5 & 22.9 & 1710 & 83 & 4000 \\
\hline 7 & Jiuhua Mt. & 117.83 & 30.54 & 1.15 & 213 & 1721.3 & 16.10 & 1.2 & 25.8 & 1746.6 & 80 & 3980 \\
\hline 8 & Tiantangzhai & 115.77 & 31.13 & 1.25 & 220 & 1916 & 12.60 & 2.7 & 27.9 & 1800 & 80.7 & 4800 \\
\hline 9 & Mingyue Mt. & 114.95 & 27.97 & 1.30 & 230 & 1450.9 & 17.10 & 2.4 & 26 & 1450 & 82 & 4100 \\
\hline 10 & Lushan Mt. & 115.98 & 29.53 & 1.10 & 240 & 1836.6 & 15.10 & 1.1 & 22.6 & 1489 & 85 & 3198 \\
\hline 11 & Wuyi Mt. & 117.75 & 27.85 & 1.00 & 240 & 2110 & 12.60 & 1.6 & 19.5 & 1434 & 84 & 4812 \\
\hline 12 & Daiyun Mt. & 118.20 & 25.67 & 1.20 & 245 & 2560 & 14.50 & 5.5 & 20.3 & 1750 & 83 & 5000 \\
\hline 13 & Mufu Mt. & 113.33 & 28.98 & 1.30 & 232 & 1978.8 & 13.10 & 1.2 & 24 & 1450 & 80 & 4000 \\
\hline 14 & Shunhuang Mt. & 113.00 & 26.98 & 1.75 & 270 & 1490 & 17.90 & 5.7 & 27.7 & 1455 & 81 & 4500 \\
\hline 15 & Tianmu Mt. & 119.42 & 30.32 & 1.4 & 229 & 2024 & 12.20 & -3 & 24 & 1504 & 79 & 4568 \\
\hline
\end{tabular}

Numbers in the first column correspond to the sampling sites depicted in Figure 1; Long., Lat., Alt., FFP, AP, AMT, MT_Ja, MT_Ju, SD, RH, and CT represent longitude $\left({ }^{\circ}\right)$, latitude $\left({ }^{\circ}\right)$, altitude $(\mathrm{km})$, frost-free period (days), annual precipitation $(\mathrm{mm})$, annual mean temperature $\left({ }^{\circ} \mathrm{C}\right)$, mean temperature in January $\left({ }^{\circ} \mathrm{C}\right)$ and July $\left({ }^{\circ} \mathrm{C}\right)$, sunshine duration (hours), relative humidity (\%), and accumulated temperature higher than $10^{\circ} \mathrm{C}\left({ }^{\circ} \mathrm{C}\right)$, respectively.

\section{GIS-cluster analysis}

Fundamental to gene differentiation in a spatial context are certain environmental factors, such as altitude, temperature, humidity, and sunshine, all of which are likely to influence gene polymorphisms. In this study, nine environmental variables were recorded at the sampling sites (Table 1).

All of the ecological factors and their spatial characteristics were processed by applying statistical methods (i.e., cluster analysis) to GIS data, using the digital processing system (DPS) software (Wang et al., 2010). Specifically, a distance matrix was first calculated, based on the hyperspace distance (i.e., the variation in environmental traits) between any two sites. Similar groups were then formed based on small distances, which determined how the distance between two clusters was defined (Zhou et al., 2004; Gao et al., 2011). Finally, cluster groupings were incorporated into the GIS system using the DPS software. A site category map was produced based on the GIS-cluster analysis.

\section{Morphological characterization}

To characterize phenotypic traits in each sampling site, the cone length, cone diameter, needle length, needle diameter, fresh weight of needles (NFW), dry weight of needles (NWN), water content of needles (WC), and number of resin ducts (RD) were recorded.

Both the lengths and the diameters of needles and cones were measured using a Vernier caliper. We measured the four traits at least three times and calculated their average values. Because the low weight of only one needle may cause a large measurement error, ten needles were weighed together using an electronic balance. This method allows for 
the mean NFW, mean NWN, and mean WC to be easily calculated. At least three needles from each site were cross-sectioned, and the sections were observed under a Model BX50 optical microscope (Olympus Optical, Tokyo, Japan) with a magnification of 60 to record the RD.

\section{Molecular characterization}

From each parent tree, $100 \mathrm{mg}$ of young leaf tissue was taken and frozen in liquid nitrogen for DNA extraction, using the CTAB-based extraction technique (Lodhi et al., 1994). Each sample's DNA concentration was quantified on $1 \%$ agarose gel and then diluted to $20 \mathrm{ng} /$ $\mu \mathrm{L}$ for RAPD analysis. All of the diluted DNA samples were stored at $-20^{\circ} \mathrm{C}$ until use.

\section{RAPD analysis}

The $P$. taiwanensis DNA sequence is still unknown, so arbitrary primers must be used; in addition, RAPD is simple, fast, and inexpensive, and requires only small quantities of tissue for DNA extraction (Arif et al., 2005; Kumar and Gurusubramanian, 2011). Therefore, RAPD was used in this study.

Thirty primers were tested for PCR amplification. After preliminary testing on a few samples, 16 primers that had clear polymorphic and reproducible banding patterns were selected to assess the genetic variability of the species (Table 2).

\begin{tabular}{|c|c|c|c|c|}
\hline Primer & Sequence $\left(5^{\prime}-3^{\prime}\right)$ & No. of bands & No. of polymorphic bands & Percentage of polymorphic bands (\%) \\
\hline AW56129 & CTTGGCACGA & 10 & 9 & 90.00 \\
\hline AW56130 & ACGGCACGCA & 6 & 5 & 83.30 \\
\hline AW56131 & TTGGCACGGG & 8 & 8 & 100.00 \\
\hline AW56133 & CACCGTATCC & 7 & 7 & 100.00 \\
\hline AW56135 & CAGGCCCTTC & 6 & 5 & 83.30 \\
\hline AW56136 & AGCGTGTCTG & 8 & 7 & 87.50 \\
\hline AW56137 & GGTGAACGCT & 5 & 4 & 80.00 \\
\hline AW56138 & GGCTGCAATG & 8 & 7 & 87.50 \\
\hline AW03734 & ТССАСТССТG & 10 & 9 & 90.00 \\
\hline AW03735 & CACAGAGGGA & 7 & 5 & 71.43 \\
\hline AW03736 & GATGCCAGAC & 4 & 3 & 75.00 \\
\hline AW03738 & GGCTCCAATG & 8 & 6 & 75.00 \\
\hline AW03739 & GGGTCTCGGT & 6 & 4 & 66.67 \\
\hline AW03743 & TCTGGACGGA & 6 & 5 & 83.33 \\
\hline AW03745 & CACAGCTGCC & 9 & 7 & 77.78 \\
\hline AW03747 & CCATTCCCCA & 10 & 7 & 70.00 \\
\hline Total & - & 118 & 98 & 83.05 \\
\hline
\end{tabular}

Amplifications were carried out in $25-\mu \mathrm{L}$ volumes containing $1 \mathrm{X}$ buffer, $1 \mathrm{mM} \mathrm{MgCl}$, $200 \mu \mathrm{M}$ dNTPs, 1.7 U Taq DNA polymerase, $400 \mathrm{nM}$ primers, and $80 \mathrm{ng}$ template DNA. PCRs were performed in a thermal cycler, which was programmed for an initial denaturation step $\left(5 \mathrm{~min}\right.$ at $\left.95^{\circ} \mathrm{C}\right)$ followed by 30 amplification cycles $\left(1 \mathrm{~min}\right.$ at $94^{\circ} \mathrm{C}, 1 \mathrm{~min}$ at $38^{\circ} \mathrm{C}$, and 2 min at $72^{\circ} \mathrm{C}$ ), and one 5 -min cycle at $72^{\circ} \mathrm{C}$. The amplification products were separated by electrophoresis on $1.5 \%$ agarose gels in a $0.5 \mathrm{X}$ TBE buffer, stained with ethidium bromide, and photographed under UV light. Each amplification was repeated at least twice to identify repeatable polymorphisms. 


\section{Data analysis}

Data were scored as a 1 for the presence and a 0 for the absence of a DNA band, and each characteristic state was treated independently. For each primer, the number of different bands and the frequency of polymorphic bands were calculated. Genetic similarity and cluster analyses were performed by calculating the Jaccard similarity index and a genetic distance matrix. A dendrogram was also constructed, using the DPS software. Analysis of variance (ANOVA) was conducted on the quantitative morphological features, and homogeneous groups were determined.

\section{RESULTS}

\section{GIS-cluster analysis}

During the study period, the temperature and precipitation ranged from $-3^{\circ}$ to $27.9^{\circ} \mathrm{C}$ and from 1450 to $2560 \mathrm{~mm}$, respectively, and the RH ranged from 78 to $85 \%$ (Table 1). The distances between the sampling sites ranged from 2.2 to 3.9. Based on the cluster analysis, five clusters (Cluster I, Cluster II, Cluster III, Cluster IV, and Cluster V) were identified (Figure 2).

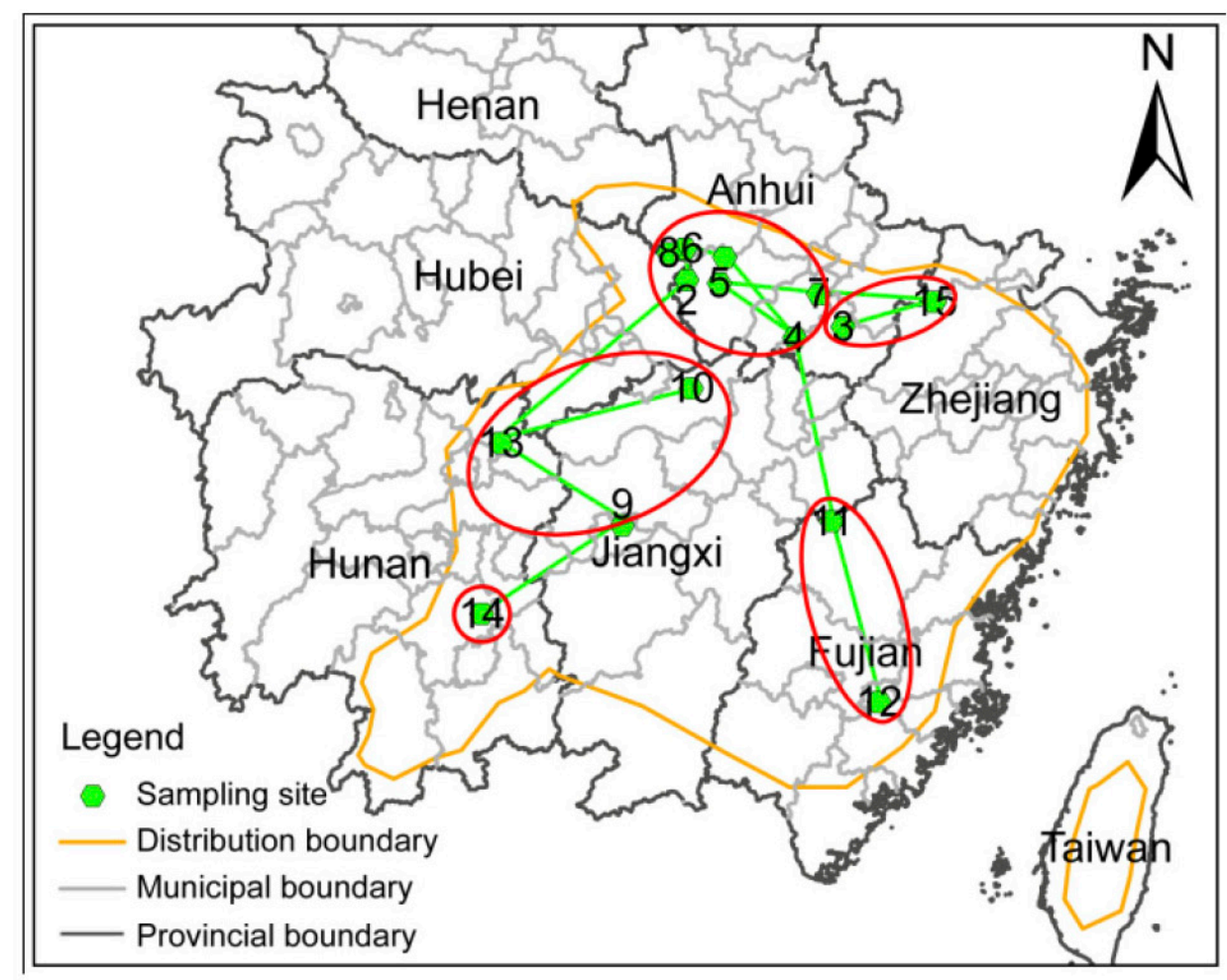

Figure 2. GIS-cluster results based on environmental variables in the sampling sites. The green line indicates the relationship between the sampling sites and the red circles represent grouping clusters. 
Cluster I was comprised of three locations (13, 9, and 10) that were separated from other populations by a mean distance of 3.2. Each site in this group had a high RH, and there was a large temperature difference between summer and winter. Cluster II contained seven locations $(1,2,4,5,6,7$, and 8$)$ that were separated by a mean distance of 3.3. These locations were all located in Anhui Province and near the Yangtze River. The precipitation in this area was seasonally variable. For example, summer precipitation accounted for one-fifth of the total AP. Cluster III was comprised of two locations ( 3 and 15) that were separated by a mean distance of 3.4. The climate in Cluster III was colder and more humid than that in the other areas. Cluster IV had two locations (11 and 12) that were separated by a mean distance of 2.5, whereas only one location (14) in Cluster V was separated by a mean distance of 3.7. The environmental variables of the Huangshan Scenic Resort (3) and Tianmu Mountain (15) were classified in the same group. The Huangshan Scenic Resort was in Cluster III, suggesting that some environmental conditions in the Huangshan Scenic Resort were different from those in the other locations, specifically its high altitude and low AMT.

\section{Morphological characterization}

The morphological traits of $P$. taiwanensis needles and cones are presented in Table 3.

\begin{tabular}{|c|c|c|c|c|c|c|c|c|}
\hline No. & $\mathrm{CL}(\mathrm{cm})$ & $\mathrm{CD}(\mathrm{cm})$ & $\mathrm{NL}(\mathrm{cm})$ & $\mathrm{ND}(\mathrm{mm})$ & NFW (mg) & NWN (mg) & WC $(\%)$ & $\mathrm{RD}$ \\
\hline 1 & $4.56 \pm 0.86$ & $2.58 \pm 0.60$ & $11.53 \pm 0.3$ & $1.17 \pm 0.7$ & $114.2 \pm 2.6$ & $32.9 \pm 3.0$ & 71.1 & 4.6 \\
\hline 2 & $4.61 \pm 0.14$ & $2.25 \pm 0.74$ & $10.88 \pm 0.8$ & $1.28 \pm 0.2$ & $103.6 \pm 6.4$ & $33.3 \pm 2.4$ & 67.9 & 6.6 \\
\hline 3 & $3.80 \pm 0.54$ & $2.19 \pm 0.14$ & $7.83 \pm 0.3$ & $0.89 \pm 0.1$ & $26.4 \pm 6.5$ & $13.0 \pm 2.2$ & 50.8 & 4.1 \\
\hline 4 & $3.69 \pm 0.49$ & $2.21 \pm 0.97$ & $7.02 \pm 0.7$ & $0.81 \pm 0.2$ & $22.6 \pm 3.8$ & $13.6 \pm 2.7$ & 39.8 & 4.4 \\
\hline 5 & $4.51 \pm 0.10$ & $2.59 \pm 0.57$ & $8.47 \pm 0.7$ & $1.22 \pm 0.3$ & $71.5 \pm 8.9$ & $21.3 \pm 4.6$ & 70.2 & 5.0 \\
\hline 6 & $6.63 \pm 0.86$ & $3.24 \pm 0.60$ & $13.87 \pm 0.7$ & $1.37 \pm 0.3$ & $79.3 \pm 1.2$ & $63.6 \pm 5.3$ & 19.8 & 5.0 \\
\hline 7 & $4.59 \pm 0.34$ & $2.59 \pm 0.33$ & $9.22 \pm 0.2$ & $1.11 \pm 0.3$ & $47.8 \pm 5.4$ & $25.3 \pm 9.2$ & 47.1 & 6.8 \\
\hline 8 & $4.56 \pm 0.11$ & $2.58 \pm 0.21$ & $12.00 \pm 0.7$ & $1.13 \pm 0.8$ & $87.9 \pm 8.5$ & $31.7 \pm 3.0$ & 63.9 & 3.8 \\
\hline 9 & $3.90 \pm 0.86$ & $2.33 \pm 0.94$ & $8.72 \pm 0.2$ & $1.12 \pm 0.2$ & $71.1 \pm 2.8$ & $27.2 \pm 2.5$ & 61.7 & 6.6 \\
\hline 10 & $3.67 \pm 0.04$ & $2.27 \pm 0.68$ & $12.97 \pm 0.7$ & $1.22 \pm 0.2$ & $124.2 \pm 4.2$ & $25.8 \pm 7.6$ & 79.2 & 7.0 \\
\hline 11 & $4.55 \pm 0.59$ & $2.41 \pm 0.76$ & $10.08 \pm 0.9$ & $1.16 \pm 0.1$ & $73.8 \pm 5.8$ & $27.4 \pm 4.4$ & 62.9 & 3.3 \\
\hline 12 & $4.66 \pm 0.29$ & $2.43 \pm 0.02$ & $9.62 \pm 0.7$ & $1.29 \pm 0.7$ & $103.5 \pm 4.2$ & $34.8 \pm 8.7$ & 66.4 & 5.6 \\
\hline 13 & $6.62 \pm 0.69$ & $3.23 \pm 0.29$ & $12.92 \pm 0.1$ & $1.20 \pm 0.2$ & $145.4 \pm 8.2$ & $53.6 \pm 7.4$ & 63.1 & 4.0 \\
\hline 14 & $4.62 \pm 0.54$ & $2.59 \pm 0.54$ & $10.23 \pm 0.2$ & $1.20 \pm 0.1$ & $100.2 \pm 5.4$ & $24.5 \pm 2.0$ & 75.5 & 6.0 \\
\hline 15 & $3.64 \pm 0.01$ & $2.25 \pm 0.74$ & $7.98 \pm 0.4$ & $0.97 \pm 0.1$ & $35.8 \pm 4.5$ & $17.9 \pm 6.7$ & 50.0 & 4.0 \\
\hline
\end{tabular}

$\mathrm{CL}=$ cone length $\mathrm{CD}=$ cone diameter; $\mathrm{NL}=$ needle length; $\mathrm{ND}=$ needle diameter; $\mathrm{NFW}=$ fresh weight of needle; $\mathrm{DWN}=$ dry weight of needle; $\mathrm{WC}=$ water content of needle; $\mathrm{RD}=$ number of resin ducts). Numbers in the first column correspond to the sampling sites in Table 1 and Figure 1.

Data were compared between the pine populations using a distance matrix based on Gower's distance, and a dendrogram was constructed (Figure 3). The dendrogram could be divided into four clusters: Cluster I contained ten populations $(1,2,5,7,8,9,10,11,12$, and 14), and was separated from the other populations by a mean distance of 2.21. These populations were characterized by a high WC, and were in Anhui, Jiangxi, or Fujian provinces. Cluster II was comprised of three populations $(3,15$, and 4$)$, and was characterized by having the lowest WC. The pines in this area grow on cliffs, particularly in the Huangshan Scenic Resort, and can probably not obtain much water from the soil, although the AP in this area is high. Cluster III (6) and Cluster IV (13) were classified as a single group. 


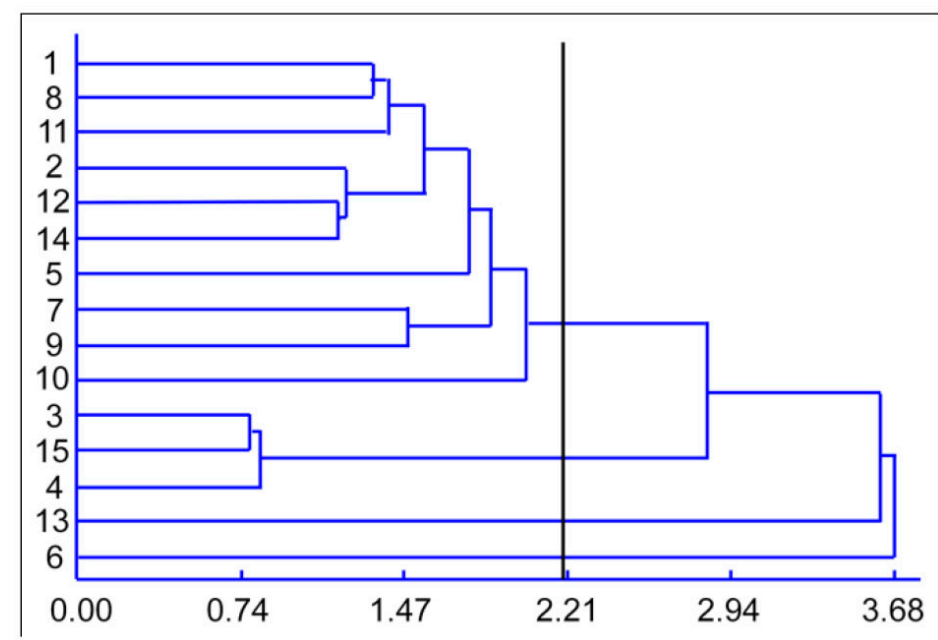

Figure 3. Dendrogram of 15 Pinus taiwanensis populations, using morphological traits and based on Gower's distance.

\section{Molecular characterization}

Using RAPD analysis, 118 bands were amplified from 16 primers with a mean of 7.8 bands per primer. The size of individual bands ranged from 150 to $2300 \mathrm{bp}$. The mean frequency of polymorphisms was $83.05 \%$ (Table 2).

A distance matrix was constructed, based on the Jaccard distance. Five clusters were identified from the dendrogram (Figure 4). Cluster I (1, 6, and 5) was separated from the other populations by a mean distance of 0.3 , and Cluster II ( 3 and 15), Cluster III $(2,8,4$, and 10$)$, Cluster IV $(7,9$, and 11$)$, and Cluster V $(12,13$, and 14) were grouped by respective distances of $0.2,0.49,0.5$, and 0.5 .

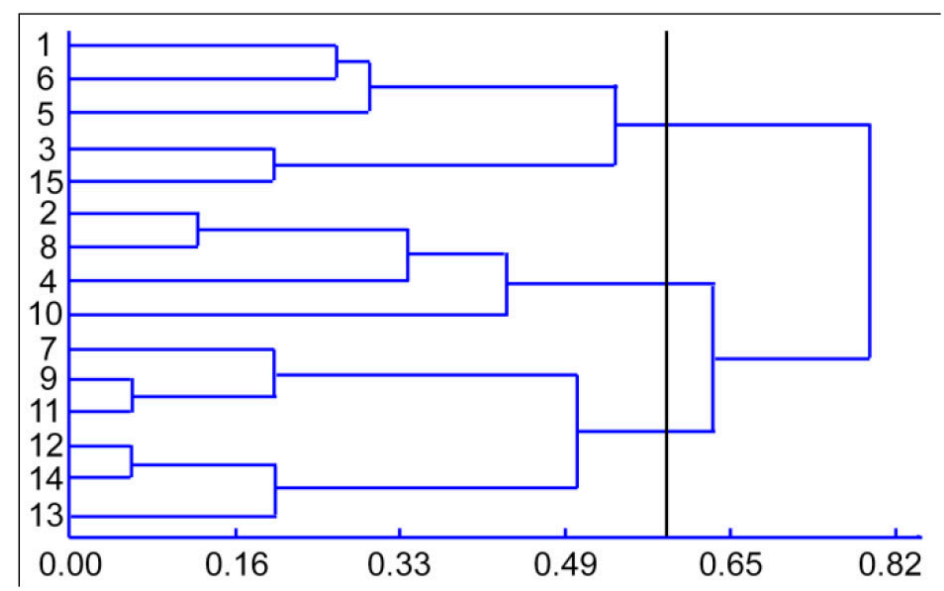

Figure 4. Dendrogram showing genetic relationships between 15 Pinus taiwanensis populations using RAPD markers, based on the Jaccard distance. 


\section{Comparison of the three methods}

Although the clustering patterns of the 15 populations differed between the three methods (i.e., GIS cluster, morphological, and molecular cluster), sites 3 and 15 were consistently grouped in the same cluster. The characteristics of the Huangshan Scenic Resort (3) were similar to those of Tianmu Mountain (15), suggesting that Tianmu Mountain is the best choice for the ex situ conservation of $P$. taiwanensis.

\section{DISCUSSION}

P. taiwanensis is an important resource for tourist resorts, and grows in many regions of China. To protect the species, we looked for a place that was suitable for its ex situ conservation. Our study compared climatic factors at 15 sampling sites using a GIS-clustering method. This geostatistical analysis method provides a simple and effective tool to delineate different categories of sampling areas at specific locations, and spatial information can be incorporated at a high level of detail (Grubesic and Murray, 2001; Tang et al., 2011).

Huangshan and Guniujiang are close to each other in Anhui Province, but the growing conditions in these two sites exhibited a large taxonomic distance, indicating that their geographical proximity did not result in ecological similarities. In contrast, the Huangshan Scenic Resort in Anhui had similar growing conditions to those on Tianmu Mountain in Zhejiang Province. Comparisons of the populations, at both morphological and genetic levels, support this conclusion. Therefore, pines in the Huangshan Scenic Resort could be transplanted to Tianmu Mountain for their ex situ conservation.

Significant positive correlations between the different markers used in genetic diversity analyses have been reported in Capsicum chinensis (Finger et al., 2010), Oxalis tuberosa (Pissard et al., 2008), and other species. This consistency, investigated using morphological traits and RAPD markers, has also been reported in Iranian sesame (Sesamum indicum) (Tabatabaei et al., 2011) and the alga Haematococcus pluvialis (Mostafa et al., 2011). The present study found a similar correlation for P. taiwanensis.

Although the two methods revealed similar mean genetic distances between populations, the clustering patterns based on the two datasets differed. The RAPD marker method was better at clustering the populations according to their geographical origin, whereas the morphological cluster method was better at clustering the populations based on their phenotypic traits. Differences might occur if morphological similarities are due to different combinations of alleles that produce similar phenotypes (Jafari et al., 2012). Differences between morphological and RAPD markers might also occur if a single gene or a few genes control the expression of morphological traits that RAPD markers fail to detect (Lin et al., 2009). This discordance might also be caused by differences in evolutionary rates between morphological characters and characters originating from a selectively neutral, non-coding DNA region (Pham et al., 2011). In addition, morphological characters have adaptive value, and molecular markers are selectively neutral (Ballentine and Greenberg, 2012). Furthermore, several other factors may affect the estimation of genetic diversity and the relationship between individuals, such as the type and number of markers used and the distribution of markers in the genome (Frascaroli et al., 2013).

The use of two or more methods provides a better understanding of genetic diversity and relationships within and between populations of a species. In this study, RAPD markers 
revealed a high level of polymorphism across $P$. taiwanensis populations. In conclusion, both morphological and RAPD markers were useful in evaluating the genetic diversity of this species of pine. P. taiwanensis should be conserved in the Huangshan Scenic Resort before it is extirpated. Future studies should attempt to improve the resistance potential and other unique traits of threatened species, particularly of the pines of the Huangshan Scenic Resort, which are extremely important in China.

The results from using three different analytical methods showed that the living conditions, phenotypes, and genotypes of P. taiwanensis in the Huangshan Scenic Resort are closest to those on Tianmu Mountain. This result may provide an important scientific basis for the protection of biodiversity in the Huangshan Scenic Resort.

\section{ACKNOWLEDGMENTS}

Research supported by the Special Fund for Basic Scientific Research of International Centre for Bamboo and Rattan (\#1632012004), the National Natural Science Foundation of China (\#31101148 and \#31300177), and the Innovation Foundation of AHNU (\#2010cxjj14).

\section{REFERENCES}

Arif M, Kousar S, Bajwa MA, Arif A, et al. (2005). Genetic diversity among rice genotypes of Pakistan through random amplified polymorphic DNA (RAPD) analysis. Pak. J. Bot. 37: 585.

Ballentine B and Greenberg R (2012). Common garden experiment reveals genetic control of phenotypic divergence between swamp sparrow subspecies that lack divergence in neutral genotypes. PLoS One 5: e10229.

Barrett SCH, Kohn JR, Falk DA and Holsinger KE (1991). Genetic and evolutionary consequences of small population size in plants: implications for conservation. Oxford University Press, Oxford.

Brush SB (1995). In situ conservation of landraces in centers of crop diversity. Crop Sci. 35: 346-354.

Clement CR, Santos RP, Desmouliere SJM, Ferreira EJL, et al. (2009). Ecological adaptation of wild peach palm, its in situ conservation and deforestation-mediated extinction in Southern Brazilian Amazonia. PLoS One 4: e4564.

Dursun A, Haliloglu K and Ekinci M (2010). Characterization of breeding lines of common bean as revealed by RAPD and relationship with morphological traits. Pak. J. Bot. 42: 3839-3845.

Finger F, Lannes S, Schuelter A, Doege J, et al. (2010). Genetic diversity of Capsicum chinensis (Solanaceae) accessions based on molecular markers and morphological and agronomic traits. Genet. Mol. Res. 9: 1852-1864.

Frascaroli E, Schrag TA and Melchinger AE (2013). Genetic diversity analysis of elite European maize (Zea mays L.) inbred lines using AFLP, SSR, and SNP markers reveals ascertainment bias for a subset of SNPs. Theor. Appl. Genet. 126: 133-141.

Gao X, Liu K and Qiu BS (2011). An investigation on the genetic background of Nostoc flagelliforme by similarity analysis of its partial genomic DNA and phylogenetic comparison of deduced related species. Acta Physiol. Plant 33: 1301-1318.

Grubesic TH and Murray AT (2001). Detecting hot spots using cluster analysis and GIS. In: The Fifth Annual Int. Crime Mapping Research Conference, Dallas and Texas.

Higgins SI, Richardson DM, Cowling RM and Trinder-Smith TH (1999). Predicting the landscape-scale distribution of alien plants and their threat to plant diversity. Conserv. Biol. 13: 303-313.

Jafari S, Alkhori L, Schleiffer A, Brochtrup A, et al. (2012). Combinatorial activation and repression by seven transcription factors specify drosophila odorant receptor expression. PLoS Biol. 10: e1001280.

Jetz W and Rahbek C (2002). Geographic range size and determinants of avian species richness. Science 297: 1548-1551.

Kumar NS and Gurusubramanian G (2011). Random amplified polymorphic DNA (RAPD) markers and its applications. Sci. Vis. 11: 116-124.

Lin KH, Lai YC, Li HC, Lo SF, et al. (2009). Genetic variation and its relationship to root weight in the sweet potato as revealed by RAPD analysis. Sci. Hortic. 120: 2-7.

Lodhi MA, Ye GN, Weeden NF and Reisch BI (1994). A simple and efficient method for DNA extraction from grapevine cultivars and Vitis species. Plant Mol. Biol. Rep. 12: 6-13. 
Martin C, Herrero M and Hormaza JI (2011). Molecular characterization of apricot germplasm from an old stone collection. PLoS One 6: e23979.

McGregor CE, van Treuren R, Hoekstra R and van Hintum TJL (2002). Analysis of the wild potato germplasm of the series Acaulia with AFLPs: implications for ex situ conservation. Theor. Appl. Genet. 104: 146-156.

Mostafa N, Omar H, Tan SG and Napis S (2011). Studies on the genetic variation of the green unicellular alga Haematococcus pluvialis (Chlorophyceae) obtained from different geographical locations using ISSR and RAPD molecular marker. Molecules 16: 2599-2608.

Nayak SA, Kumar S, Satapathy K, Moharana A, et al. (2013). In vitro plant regeneration from cotyledonary nodes of Withania somnifera (L.) Dunal and assessment of clonal fidelity using RAPD and ISSR markers. Acta Physiol. Plant. 35: 195-203.

Nazar N and Mahmood T (2011). Morphological and molecular characterization of selected Artemisia species from Rawalakot, Azad Jammu and Kashmir. Acta Physiol. Plant. 33: 625-633.

Nevo E (1998). Genetic diversity in wild cereals: Regional and local studies and their bearing on conservation ex situ and in situ. Genet. Resour. Crop Evol. 45: 355-370.

Pham TD, Geleta M, Bui TM, Bui TC, et al. (2011). Comparative analysis of genetic diversity of sesame (Sesamum indicum L.) from Vietnam and Cambodia using agro-morphological and molecular markers. Hereditas 148: 28-35.

Pissard A, Arbizu C, Ghislain M, Faux A-M, et al. (2008). Congruence between morphological and molecular markers inferred from the analysis of the intra-morphotype genetic diversity and the spatial structure of Oxalis tuberosa Mol. Genetica 132: 71-85.

Robinet C, Roques A, Pan HY, Fang GF, et al. (2009). Role of human-mediated dispersal in the spread of the Pinewood Nematode in China. PLoS One 4: e4646.

Sheue CR, Yang YP and Kuo-Huang LL (2003). Altitudinal variation of resin ducts in Pinus taiwanensis Hayata (Pinaceae) needles. Bot. Bull. Acad. Sin. 44: 305-313.

Singh SR, Dalal S, Singh R, Dhawan AK, et al. (2013). Evaluation of genetic fidelity of in vitro raised plants of Dendrocalamus asper (Schult. \& Schult. F.) Backer ex K. Heyne using DNA-based markers. Acta Physiol. Plant 35: 419-430.

Tabatabaei I, Pazouki L, Bihamta MR, Mansoori S, et al. (2011). Genetic variation among Iranian sesame (Sesamum indicum L.) accessions vis-a-vis exotic genotypes on the basis of morpho-physiological traits and RAPD markers. Aust. J. Crop Sci. 5: 1396-1407.

Tang ZY, Fang JY, Sun JY and Gaston KJ (2011). Effectiveness of protected areas in maintaining plant production. PLoS One 6: e19116.

Tyrka M (2004). Fingerprinting of common wheat cultivars with an Alw441-based AFLP method. J. Appl. Genet. 45:405-10.

Wang K, Zhong J, Zhang DD, Qiu P, et al. (2010). Genetic diversity analysis of 16 genotypes of Houttuynia cordata Thunb by SRAP. Crop Res. 24: 30-35.

Wu G, Huang M, Duan R and Zhao K (2006). Disturbing effects of tourism on species diversity in Pinus taiwanensis communities. Acta Ecol. Sin. 26: 3924-3930.

Yang B, Mota M and Vieira P (2004). The pinewood nematode, Bursaphelenchus xylophilus. Proceedings of an International Workshop, University of Évora, Portugal, 21-24.

Zhang LQ (1990). Population-structure and dynamics of Pinus taiwanensis Hayata at Songyang County, Zhejiang Province, China. Vegetatio 86: 119-129.

Zhou D, Xu J, Radke J and Mu L (2004). A spatial cluster method supported by GIS for urban-suburban-rural classification. Chin. Geogr. Sci. 14: 337-342. 